\title{
Un papel manchado con rouge. "Amorales suburbanos" en el discurso periodístico durante el primer peronismo. La Plata, 1948
}

\author{
A napkin stained with rouge. "Suburban amorales" in the journalistic discourse \\ during the first peronism. La Plata, 1948
}

Paula E. Román

paularoman87@gmail.com

Centro de Investigaciones SocioHistóricas, Instituto de

Investigaciones en Humanidades y Ciencias Sociales, Universidad Nacional de La Plata, Argentina

Recepción: 12 Febrero 2021

Aprobación: 03 Mayo 2021

Publicación: 01 Marzo 2022

Cita sugerida: Román, P. E. (2022). Un papel manchado con rouge. “Amorales suburbanos” en el discurso periodístico durante el primer peronismo. La Plata, 1948. Sociohistórica, 49, e163. https://doi.org/10.24215/18521606e163
Resumen: Este trabajo aborda representaciones sobre “amorales" en la prensa gráfica durante el primer peronismo. Normalmente la homosexualidad masculina aparecía representada en las noticias policiales en relación a hechos delictivos o violentos, configurando una mirada estigmatizante que la asimilaba al "bajo fondo". Sin embargo, el estudio de caso que aquí proponemos expresa ciertos matices en aquella figuración dominante. Siguiendo la cobertura de un asesinato, el trabajo muestra que su protagonista comulgaba con un conjunto de identificaciones ligadas al peronismo, que impidieron inscribirle en los términos tradicionales del "amoral" como criminal. Esto fue así especialmente en el diario El Plata, un informativo que apelaba al público obrero. Partiendo del análisis de la noticia como discurso público se abordan un conjunto de representaciones sobre géneros y sexualidades, inscritas en un contexto provincial, que recupera asimismo la dinámica de barrio como escenario y contexto.

Palabras clave: Peronismo, Homosexualidad, Amorales, Prensa, Géneros.

\begin{abstract}
This paper proposes an approach to representations of "amorales" in the press during the first peronism. Male homosexuality often appeared in the police news related to violent crimes, configuring a stigmatizing point of view which asimilated it to the "bajo fondo". However, this case study expresses certain nuances in that dominant figure. Following the coverage of a murder, this study shows that its protagonist communed with a set of identifications related to peronism, which prevented him from being registered in the traditional terms of "amoral" as a criminal. This was especially so in the newspaper El Plata, aimed to the working class. Starting from the analysis of the news as public discourse, a set of representations about genders and sexualities are addressed, inscribed in a small town context, which also recovers the neighborhood dynamics as setting.
\end{abstract}

Keywords: Peronism, Homosexuality, Amorales, Press, Gender. 


\section{INTRODUCCIÓN ${ }^{1}$}

El presente trabajo tiene por objetivo indagar en las representaciones sobre homosexualidad masculina en la prensa gráfica, durante el primer peronismo. A tal fin, se propone un estudio de caso centrado en un hecho policial: el asesinato de un ferroviario retirado, de nombre Horacio Palma, ocurrido el 8 de Octubre de 1948 y el de su madre anciana como parte del mismo episodio. Padre de dos hijos, Palma se encontraba separado de su esposa, instalándose con su madre en un terreno ubicado en Villa Elvira, en las afueras de La Plata. Allí se encontraban "las casitas gemelas", dos construcciones modestas, de idéntico diseño que operan como escenario de los acontecimientos. La cobertura de los diarios en sus días posteriores permite seguir de cerca la investigación que, con matices, acaba reconstruyendo un entorno homoerótico en la vida del jubilado. Esta línea aportó la clave para dar con quien sería su asesino y amante, un joven peón rural, llamado Ángel Valdez, migrante del interior de la provincia de Buenos Aires.

Los "amorales" fueron un tema recurrente en las noticias de los años 40 y 50 . Construida como un significante abierto, la "amoralidad" designaba un conjunto amplio de inscripciones que abarcaban la corrupción prostituyente de mujeres y menores, los actos violentos de patotas, violadores y acosadores, pero también otras prácticas no delictivas como las relaciones homosexuales (Acha, 2013). Aunque no se encuadrara como delito en el código penal, ser homosexual y expresarlo públicamente a menudo costaba la detención policial, amparada en la contravención de "escándalo público" (Sebreli, 1997). ${ }^{2}$

Por lo mismo, los "amorales" solo aparecen en el marco de las noticias policiales, a propósito de una muerte misteriosa o un hecho delictivo. Por norma general, en este último caso, el carácter "amoral” de los sujetos involucrados trascendía la oposición común entre la víctima y victimario para igualarles en la inscripción general del "bajo fondo". La tipificación de una y otra figura resultaba así equivalente, pues por encima de los hechos y ante todo se trataba de sujetos "consustanciados en su amoralidad".

El caso que proponemos aquí exhibe, sin embargo, un tratamiento desigual de aquellas figuras, justificando su elección. Mientras Ángel Valdez encarnó la homosexualidad como perversión, el registro periodístico resultó más benevolente con Palma, quien era referenciado en términos de "Señor" ¿En qué se asentó aquella diferencia? La hipótesis de nuestro trabajo sostiene que, en su carácter de obrero ferroviario y padre de familia, Palma armonizaba con un núcleo de identificaciones ligadas al peronismo, que coexistían de manera problemática con un entorno homoerótico. De ello resulta un abordaje signado por tensiones que impedían la condena moral sin más, como habitualmente hacía la prensa al comunicar noticias sobre "amorales". La historia de Palma se inscribía en el marco de un discurso que velaba por la "sana moral" del "trabajador auténtico". Esta lectura es especialmente evidente en El Plata, un periódico peronista de la ciudad de La Plata que dedicaba sus páginas a informar al público obrero, así como vindicar la condición popular. En ocasiones, ante la muerte de un trabajador, el diario hacía uso de una narrativa heroica que buscaba recuperar cierta esencia en el hombre de trabajo. El obrero era ante todo un hombre bueno, honesto y valiente, y al ser padre de familia, era también heterosexual. Desde este lugar, los afectos de Horacio Palma serían presentados como “equívocos", es decir, "errores" que en tanto tales podían enmendarse. Por contraparte, el diario acentuó la diferencia con el perpetrador, cuya sexualidad era expresión de sus "bajos instintos", quedando atada a una inscripción biológica inmodificable. ${ }^{3}$

Otro registro aporta El Argentino, un periódico asociado a un público de clase media, que puso énfasis en lo procedimental de las pericias judiciales, evitando una aproximación que recuperara la homosexualidad abiertamente. Esta aparece aquí como un "innombrable", en un recorrido poblado de alusiones evasivas. Este tratamiento disímil en periódicos que apuntaban a públicos diferentes es revelador de las concepciones de moral sexual según la clase social: mientras que el diario obrero habló con mayor libertad de las sexualidades no heteronormadas (inscribiéndolas en una mirada binaria y heterosexista), El Argentino resultaba más pudoroso, llegando al punto de no nombrarlas, con el fin de "proteger" a sus lectores. 
Para la justificación del caso partimos de una perspectiva microhistórica según la cual el abordaje de lo particular permite reconstruir un universo social más amplio (Ginzburg, 2016). La nutrida cobertura del episodio de las “casitas gemelas", aun en su particularidad, habilita una amplia gama de reflexiones no siempre convencionales que nos permite asomarnos a vivencias frecuentemente desapercibidas. La sociabilidad homoerótica en su inscripción barrial y el contexto provincial son algunos de los temas que este artículo aborda de manera articulada.

Se propone así una estructura en cuatro momentos. En el primero se repasa el abordaje del tema en la historiografía. A continuación, pondremos el foco en el diario El Plata ${ }^{4}$ con el fin de mostrar su enfoque editorial y el tratamiento habitual que el periódico daba a las identidades no convencionales, consideradas ampliamente, permitiéndonos establecer puntos de continuidad y contraste con el episodio de las "casitas gemelas". Finalmente, los dos últimos apartados trabajan las figuras de Palma y la de su amante y agresor, Ángel Valdez, en un análisis que busca mostrar el tratamiento diferenciado que obtuvieron.

\section{REFERENCIAS TEÓRICAS E HISTORIOGRÁFICAS.}

Con la canonización del modelo familiarista durante el primer peronismo, se produjo a la vez la emergencia de un conjunto de identidades que lo excedían, constituyéndose como "lo otro" (Acha y Ben, 2004; Cosse, 2008). El caso de la homosexualidad masculina es particularmente evidente en las fuentes que consultamos, expresando cierta preocupación por parte de la prensa y el Estado en relación a las derivas de la masculinidad argentina. ${ }^{5}$ Acha (2013) ha mostrado que esta se representaba en los términos de costumbres foráneas, relegadas a las alcobas de algunos extranjeros de clase alta y, por lo tanto, ajenas a los hábitos nacionales. Por lo mismo fue especialmente atribuida al "porteñismo" como expresión de displicencia frente a los valores nacionales, y en consecuencia falta en la "verdadera" hombría que encarnaría, en cambio, el obrero criollo.

Por su parte, las miradas que se impusieron desde el campo médico irradiaron sentidos autorizados sobre "lo normal", así como la definición del cuerpo sano. Ya desde fines de siglo XIX y principios del $\mathrm{XX}$, el discurso médico positivista operó en la patologización de la homosexualidad, en un contexto definitorio para las fronteras de la identidad nacional (Salessi, 1995). La correspondencia entre genitalidad e identidad se cimentó entonces en el dimorfismo sexual. Según este orden del género, las personas que sentían deseo por otras de su mismo sexo o desafiaban en algún punto la atribución de género, presentaban patologías que alteraban lo natural (Miranda, 2015). Los años del primer peronismo expresarían la cristalización de aquellas doctrinas y del campo médico como voz autorizada más allá del ámbito disciplinar (Ramacciotti y Valobra, 2006). Las intervenciones sobre cuerpos intersexuales para asegurar una supuesta correspondencia entre genitalidad e identidad es sin dudas una muestra de la violencia que expresaron frente a la "ambigüedad" (Maffia, 2003; Ben, 2000). Si bien el conocimiento científico descansaba sobre la premisa de verdad, a menudo los galenos basaron sus postulados en la religión y sus creencias personales (Gorza, 2010).

El poder militar también se inscribió en la arena del debate sobre sexualidad masculina, según se refleja en las discusiones por la habilitación de prostíbulos cercanos a los cuarteles y el conflicto con la Iglesia Católica (Guy, 1991). ${ }^{6}$ En sus intercambios, los coroneles trazaron las fronteras de la masculinidad compartiendo un conjunto de definiciones sobre virilidad que incluían la necesidad de "descarga" como condición de salud para el correcto desempeño del oficio (Simonetto, 2019). Las relaciones sexuales entre varones eran, desde esa perspectiva, una consecuencia indeseada de la abolición de la prostitución reglamentada, o la "imposibilidad de descarga”, junto con las violaciones y la masturbación, entre otros. Por lo demás, era común en los cuarteles, hospicios, cárceles y otros ambientes de reclusión. La sociedad argentina tuvo ocasión de comprobarlo en 1942, a propósito del conocido "escándalo de los cadetes" que llevó a la arena pública el debate sobre las prácticas homosexuales en el ejército. 
En cuanto a la prensa, si bien las noticias consultadas recogen en gran medida la impronta descrita, el llamado caso de "las casitas gemelas" revela un mundo de afectos, sociabilidades y deseo que trasciende ampliamente la inscripción normativa. Lejos de lo excepcional, lo extranjero o siquiera la expresión de vanidad de las clases altas porteñas, este episodio nos acerca la historia de dos trabajadores en el ámbito suburbano de la ciudad de La Plata. Un cúmulo de novelas, biografías y experiencias ha constituido material fundamental para el estudio del homoerotismo en la Ciudad de Buenos Aires (Peralta, 2013). Sin embargo, el escenario platense y provincial es aún novedoso y nos lleva a iluminar su imbricación con la red de migraciones internas y con la dinámica interclasista del primer peronismo. Por añadidura, la figura de Horacio Palma expresa una trayectoria que condensaba dos significantes construidos normalmente como opuestos: la paternidad y la homosexualidad.

El trabajo que proponemos aquí se vale de las fuentes trascendiendo el hecho criminal: no se analiza el episodio del crimen ni los procedimientos penales. Se trabaja en cambio con el tratamiento que la prensa dio a la sexualidad de sus protagonistas, atravesada por un conjunto de valoraciones específicas de los años peronistas, relativas al mundo del trabajo y la familia. Los diarios presentan una nutrida intertextualidad por lo cual el discurso periodístico se aborda asumiendo la polifonía de voces que de hecho expresa (Van Dijk, 1990). Allí se pueden ver informaciones (y opiniones) proporcionadas por vecinos, familiares, entrevistas con la policía y transcripciones de las declaraciones del poder judicial, mostrando que los periodistas tenían acceso a los expedientes. No perdemos de vista que aquellos son registros parciales y expresan lo que el periodismo elegía destacar. Sin embargo, los fragmentos hacen inteligible el proceso por el cual definían qué era lo anoticiable y qué no: no todo valía la pena de ser contado. Por último, nuestra mirada se orienta por el concepto de heterosexualidad obligatoria (Rich, 1986). Ideado para visibilizar la existencia lesbiana, este concepto expone el carácter político de la heterosexualidad como institución y modelo que arroja fuera de la norma a otras identificaciones y sexualidades posibles. Los diarios que estudiamos, inscritos en la moral sexual de su época, narraron aquellas vidas desde el un punto de vista heterocéntrico, forzándolas a entrar en el esquema binario "mujer o varón".

Veremos a continuación el tratamiento habitual que El Plata dio a las identidades no convencionales, consideradas ampliamente, en un relevamiento sistemático del año 1948, cuando sucedió el episodio de las "casitas gemelas".

\section{2. “Amorales" en el discurso periodístico: el diario El Plata.}

Fundado en 1946, El Plata era un informativo de la capital provincial que se ocupaba de noticias relativas a la ciudad y su cordón industrial, los distritos de Berisso y Ensenada. No obstante, se presentaba como un matutino "para todo el país" y cubría más ampliamente las novedades de la Capital Federal, el Gran Buenos Aires y las provincias. Como periódico bonaerense, asociado a la gestión del gobernador Domingo Mercante (1946-1952), primero, y a Carlos Aloé (1952-55) después, solía recoger su obra de gobierno así como publicar balances y comunicaciones oficiales.

Con todo, El Plata era bastante más que un periódico oficialista. Su enfoque general se destacaba por la celebración de la condición obrera, por lo que las noticias de los distritos industriales obtenían un lugar privilegiado. La fotografía de los trabajadores, la vivienda y las familias solían componer escenas habituales en sus páginas. Las publicaciones relativas a los accidentes de trabajo y los nombres de sus perjudicados, a quienes se deseaba una pronta recuperación, mostraban un interesante contraste con las "sociales" de diarios conservadores, donde se velaba por la salud de las aristocracias locales. Como "voz amiga de los trabajadores", no escatimó en entrevistas a personas comunes, y aunque en ocasiones la intervención guionada de aquellas voces es palpable, en otras, el registro resulta genuino, permitiendo un acercamiento privilegiado a los testimonios. 
En la atención que El Plata dirigió a las representaciones sobre lo popular produjo también imágenes modélicas en torno a la masculinidad obrera, frente a las cuales sus "desviados" emergían como sujetos singulares, cuyas historias se volvían anoticiables. En este apartado nos ocuparemos del modo en que este periódico abordó aquellas identificaciones que se corrían de la norma heterosexual, tomando como recorte una cobertura exhaustiva del año 1948, cuando sucedió el episodio de las "casitas gemelas". Ese año se publicaron 16 noticias: todas aparecen en la sección policial.

Como antecedente inmediato, sin embargo, el caso más destacado pertenece a 1947: se trata del asesinato del belga Buffin de Chasal, ocurrido a manos de un grupo de jóvenes con quienes mantenía encuentros sexuales ocasionales. ' Su historia es relevante en tanto condensaba un conjunto de características que instituyeron una matriz de lectura para futuros episodios: el origen foráneo de su protagonista, la mención al "instinto sexual" y el descontrol al encontrar la muerte en medio de una orgía juvenil, la inscripción subterránea de la vida "amoral”, y el final trágico de toda experiencia que se corriese de la norma genérica. La prensa actualizó su nombre una y otra vez, cristalizando como referencia obligada para referir aquellas identidades que no se atrevían a nombrar.

Los cronistas, además, solían destinar un párrafo introductorio a enumerar una nutrida cronología de sucesos donde el del belga era solo el más famoso. En efecto, se listaban numerosos "escándalos" con la costumbre de publicar las direcciones, apelando a que los lectores las recordarían de primicias previas. Así, por ejemplo, una introducción versaba: "se repetiría el caso del rentista inglés asesinado en la calle Brasil, el de F. en la calle Corrientes, el del parque Lezama y el del más reciente de la calle Esmeralda donde fue hallado muerto el portero". ${ }^{10}$ Esto no solo reflejaba el carácter de cotidianidad de los "casos", sino que al ser inscriptos en un marco de referencia preestablecido, mostraban también que la homosexualidad era reconocida como un fenómeno específico, normalmente asimilado al delito.

tro ejemplo puede dar cuenta del tono general de aquellas coberturas. F. C., un trabajador doméstico de la Capital Federal, apareció muerto en las adyacencias de la cancha de River. El Plata lo presentaba como poseedor de una "personalidad ambigua": "catalogado como amoral, alternaba con individuos del bajo fondo". ${ }^{11}$ Según el informativo "lo explotaban inicuamente substrayéndole los escasos recursos que lograba con su oficio de mucamo en un chalet de Belgrano". Un conjunto de características físicas se reconstruían para describirle. Era "atildado en el vestir", "de facciones juveniles, casi imberbe", "aparentaba tener 30 a 35 años pero las comprobaciones hechas en sus documentos de identidad lo hacen aparecer con 52 años cumplidos". 12 En este caso, características como el buen vestir y la prolijidad eran vistos como una coquetería excesiva para un varón. Del mismo modo, las facciones juveniles eran interpretadas como rasgo de una masculinidad disminuida, contraria a la barba como expresión de madurez sexual. Finalmente, y a raíz de la comprobación de sus "costumbres amorales", la policía había efectuado "una amplia razzia" de muchachos que frecuentaban las zonas de Núñez y el bajo Belgrano para dar con el asesino. Más adelante, y una vez hallado el responsable, el diario confirmaba una máxima construida en la mayoría de los casos de homicidio: "el matador" sería "otro amoral". Afirmaciones como esta tendían a desdibujar los polos "víctima y victimario", resultando de ello un estatus equivalente entre sujetos que, en tanto "amorales", quedaban integrados al "hampa" o "la mala vida" sin distinciones.

Cuando no se trataba de episodios trágicos como los descritos, se reponían eventos de robos, estafas y escapes. En dos ocasiones las notas se refirieron a "amorales tocados con prendas femeninas". En uno de ellos se trataba de "dos rosarinos que tocados atractivamente, (...) emprendían la conquista de sus víctimas de sexo masculino, para llevarlas a lugares apropiados o para tener acceso a su domicilio donde daban sus fructíferos golpes". ${ }^{13}$ Otro caso refería a un encausado que habría escapado de la cárcel "vestido de mujer”. El detenido consiguió introducir al establecimiento "todo un equipo de mujer, no descuidando detalles relativos al maquillaje femenino, según lo revela la presencia de polvos de rouge y afeites que se hallaron en el cuarto de baño". ${ }^{14}$ 
Aunque no es posible determinar la identidad autopercibida en estas y otras historias, las mismas resultan reveladoras de la mirada periodística sobre el tema inscritas en la matriz heterocéntrica que remitía al esquema binario. En estos casos las crónicas permiten concluir que la trasgresión del género acarreaba peligrosas consecuencias. Asimismo, se reponen propósitos accesorios para la configuración de una apariencia femenina (la estafa, el escape). Sin embargo, la seducción representaba mucho más que una "tapadera", expresando de hecho que ese deseo tenía lugar. La misma nota citaba otra referencia en relación a una persona apodada "La Princesita de Borbón", "un famoso delincuente porteño" que operaba igualmente en Montevideo y "acompañaba sus asaltos de fracturas y lesiones que sus enamorados debieron ocultar, para no ser objeto de burlas y bromas". ${ }^{15}$ La alusión a las burlas exponía la vergüenza homofóbica de quedar "al descubierto" tras haber sido seducidos por "amorales en papel de dama”. Según ha expresado Kimmel (1997), "el terror homofóbico" transcurre como el miedo a ser desenmascarado y exponer la propia vulnerabilidad de la masculinidad, un estatuto siempre en crisis. Los periódicos hicieron uso de la burla en numerosas oportunidades a propósito de sujetos que trasgredían el orden de género, develando la existencia de un público que las aprobaría.

En casos menos espectaculares, las noticias pusieron mayor énfasis en las víctimas de aquellas estafas y abusos. Así, por ejemplo, tras una denuncia se identificó a grupo de amigos que "se dedicaban a buscar amorales, a los que después invitaban al domicilio y los hacían víctimas de despojos". ${ }^{16}$ Los jóvenes habían sido denunciados por un italiano de oficio encerador que fue seducido, maniatado y despojado de su reloj. El caso reveló que la banda ya había embaucado a otros dos hombres más.

Los intercambios sexuales por dinero configuraban otro orden de novedades. En Rosario, un asesinato ocurrido en un entorno de clase alta, reveló la pista de un auto que se movía en tres ambientes: la salida del cine, un parque y la estación del ferrocarril. Tras una redada, se descubrió que en el auto se hallaba W.L., un conocido empresario de origen alemán, que frecuentaba aquellos sitios en busca de muchachos jóvenes. Este hombre actuaba en articulación con otros dos que se encargaban de acercar al vehículo a quienes accedían, luego de ofrecerles dinero. El periódico habló de "viciosos organizados", recordando el caso de Buffin de Chasal, una vez más, y destacando el carácter extranjero del protagonista, así como su pertenencia a un sector acomodado. ${ }^{17}$ Por añadidura, y en un recurso que se repetía oportunamente, el noticioso ampliaba en la misma página con otras notas relacionadas al tema. El resaltado "Alarma en Sidney el homosexualismo" sostenía que "la perversión homosexual ha llegado a tales proporciones que se han formulado advertencias a los padres de escolares. Hay complicados conocidos hombres de negocios". ${ }^{18}$ Este es el único registro en donde se actualiza la palabra "homosexual" sin ambages: no casualmente, en alusión a un episodio que sucedía en el extranjero.

De este modo, las noticias recabadas tienden a confirmar aquellas definiciones estancas de homosexualidad, mencionadas en el apartado anterior, en relación a un fenómeno foráneo, ligado sin matices a la corrupción de menores, con insistencia en la clase alta y, cuando el caso se daba entre los sectores populares, en articulación con el delito. ${ }^{19}$

Finalmente, y en adición a lo expresado, los diarios consultados ofrecen escasa representación de homosexualidad femenina, ${ }^{20}$ si se compara con la magnitud de noticias que abordaron la masculina en este período. $^{21}$

A continuación abordaremos el caso de las "casitas gemelas", atendiendo a las continuidades que el mismo expresa en su inscripción más general, así como las particularidades en el tratamiento de la figura de Horacio Palma. 


\section{3.}

\section{3. a. ¿Mujer o varón? Un papel con rouge que atentaba contra interpretaciones binarias.}

Un tumulto de vecinos y curiosos se concentraba en las afueras de la finca de Villa Elvira. Allí se encontraba la policía y los funcionarios judiciales desorientados frente al hallazgo de una pista que no podían identificar con claridad. Según indicaba El Plata, "durante la prolija inspección ocular que se llevó a cabo en la casa, se encontró un papel con la marca de unos labios pintados, como si alguien se hubiera limpiado la boca con ellos”. En procura de hallar a la dueña de aquel labial, los investigadores detuvieron a dos vecinas del barrio, quienes "mantenían amistad íntima con el señor Palma". ${ }^{22}$

El Argentino sostuvo sobre la misma pista que "de por sí, el hallazgo del papel con rouge demuestra que Palma era visitado en su casa por una o más damas". ${ }^{23}$ Las sospechas recayeron especialmente sobre una vecina joven, migrante del interior, que apodaban "la Criolla". Los diarios cristalizaron su imagen en dos rasgos que se repetirían numerosas veces: la Criolla era "morocha y gruesa”. Según los vecinos, esta se paseaba seguidamente por el terreno de los Palma, entrando y saliendo con naturalidad de la casa.

Como se había sabido que una de esas concurrentes era una criolla joven que acompaña al cuidador de una quinta de la zona y además se conoció un antecedente relativo a la vinculación de ella con Palma, los empleados policiales la detuvieron y la interrogaron sobre si era quien se había limpiado el rouge de los labios (...) en la forma en que lo delataba el papel encontrado. ${ }^{24}$

La mujer era además sospechada por el hallazgo de una pista complementaria: la huella de un tacón grabada en el lodo del terreno que permanecía húmedo tras las continuas lluvias.

El rastro más patente correspondía al tacón de un zapato y se infería que su dueña había caminado a lo largo de la finca. Se recogió cuidadosamente el molde de la pisada (...) y se efectuaron comparaciones con el taco de zapatos de algunas mujeres. ${ }^{25}$

En todos los casos, las pericias arrojaron resultados inciertos. Al ser interrogada sobre el labial encontrado en la escena, la mujer argumentó que no se correspondía con el que ella usaba, y añadió que no concurría a la casa de Palma desde hacía varios días. No conformes con ello, los empleados de la policía secuestraron su lápiz. "Efectuada una comparación de color con el de las manchas del papel, pudo advertirse que el del lápiz de la sospechada (...) es distinto". ${ }^{26}$

El raconto de episodios a propósito de las vecinas muestra el conjunto de indagaciones que se hicieron detrás de una huella asumida inmediatamente como signo de feminidad. La resistencia a una lectura que habilitara un vínculo homosexual en la vida del Palma, les obligó a tomar por sendas que pronto serían descartadas por inconsistencia. Tras probarse la inocencia de la Criolla, la búsqueda se desplazó a una tercera mujer que nunca pudieron encontrar aclarándose en este punto que "si bien no pudo ser la autora material del hecho, pues la violencia de los golpes revelan un criminal de físico fuerte, bien puede suministrar los datos necesarios para orientar la pesquisa". ${ }^{27}$ Las narrativas coexistían de manera contradictoria ante la imposibilidad de figurarse alternativas al modelo "mujer o varón”. Asimismo, y asumiendo en este punto la existencia de un hombre en la escena, las explicaciones reencausaron la lectura hacia patrones heterosexuales. La detención del novio de la Criolla es especialmente reveladora de aquella matriz: su móvil serían los celos ante un posible vínculo entre su compañera y Palma, fundados en el tiempo que esta pasaba en aquella casa.

Para facilitar las interpretaciones, los comunicadores pusieron a disposición del público imágenes donde se plasmaban las principales hipótesis del caso. En aquellas ilustraciones incorporaron figuras femeninas como parte de la escena, alimentando la presunción de heterosexualidad (Figura 1). Por su parte, los varones incorporados en la cronología serían furiosos acreedores impagos, o personas cuya presencia se justificaba por causas relacionadas al dinero, otro significante de una masculinidad tradicional. 
FIGURA 1

Representación gráfica de las hipótesis del caso. El Plata, 6 de octubre, 1948.

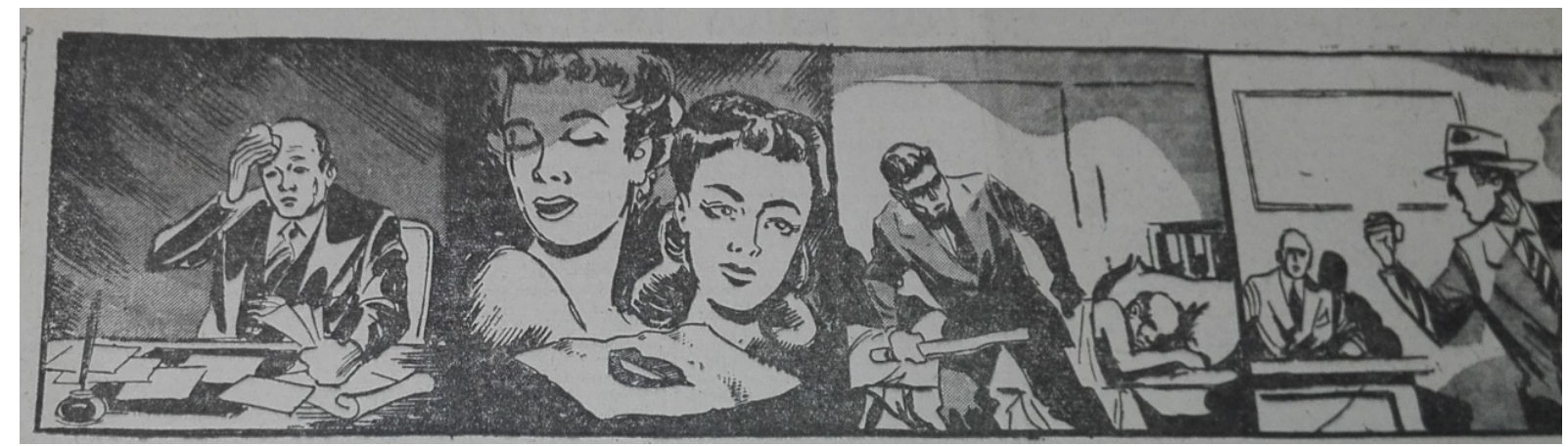

De manera superpuesta aunque reservada, la justicia comenzó a trabajar en otra línea de investigación sugerida por el peso del rumor entre los informantes: la existencia de un entorno homoerótico en la vida de Horacio, hipótesis que ofrecería mayor coherencia en el escenario planteado, según veremos. Los periódicos revisitaron entonces su figura en una aproximación que, a pesar del tono conservador, resultaba más realista. Sostuvieron que Palma dedicaba su vida de jubilado a actividades que lejos quedaban de aquellos días como controlista ferroviario. Según El Argentino, se había convertido en un "experto en belleza femenina", efectuando tareas de peluquería y maquillaje, lo que explicaba no solo la insistencia de la Criolla con sus visitas, sino la presencia cotidiana de varias vecinas pululando por la finca. "Certifica tal actividad el hallazgo en uno de los cajones de su mesa de luz de varios potes con cosméticos, frascos con tinturas para el cabello, y otros de agua oxigenada y algunos prospectos sobre el uso de tales ingredientes" ${ }^{28}$ Más adelante, y por primera vez, el cronista retomaba una aproximación algo más certera sobre la pista del rouge, sosteniendo que Horacio: "se dedicaba a aplicar a mujeres que acudían a entrevistarlo y no se sabe si también a sí mismo, tratamientos de belleza". ${ }^{29}$

Esta duda que el diario dejaba planteada, acaso sujeta a la interpretación del público, será recogida en todo derecho por El Plata, que buscó de manera algo más transparente instruir a sus lectores sobre la existencia de otros órdenes del género, aún a costa de su propia mirada.

La frecuentación de mujeres de escaso acicalamiento y coquetería, no justifica por otra parte, la presencia de afeites y demás elementos de embellecimiento que no son patrimonio exclusivo de las representantes del bello sexo, sino que también son utilizados por quienes tratan de emularlas. ${ }^{30}$

La idea del "émulo" y el "bello sexo" resistían la ambigüedad frente a una subjetividad que quebraba los límites del género. El conjunto de signos externos que hacen a la expresión de la identidad (como la ropa o el maquillaje) emergía en estas miradas como "agregados estéticos" que vanamente buscaban torcerle el brazo a la biología. Siguiendo a Buttler, Salessi ha señalado que "la exposición de las formas, el vestido y los trajes vistosos, la entonación de voz y los modales, la actitud amanerada y en general, todo el gran cuidado del bien parecer" (1995, p. 251), generaban gran ansiedad en los demás al cuestionar "la verdad del género". Sin dudas esa ansiedad es perceptible en las crónicas, junto con cierto tono de burla. Por si quedara algo que aclarar, refirieron que "aquel verdadero arsenal de cosméticos, polvo, rouge, tinturas, no denuncian precisamente a mujeres que buscaran agradarle al morador de la casa”, todo lo cual permitía dudar, ahora sí, "sobre el sexo equívoco de esos labios que aparecen impresos en el papel hallado en la finca" ${ }^{31}$

A pesar del tono moralista en estos registros, los mismos revelan que aquella peluquería de barrio, relegada a los fondos de un terreno suburbano, configuraba un espacio de sociabilidad donde géneros y sexualidades no quedaban necesariamente atados a los modelos hegemónicos. Los vecinos constataron "la frecuentación de la casa por gente joven y las relaciones de la víctima con algunos muchachos". ${ }^{32}$ En otra ocasión se había 
visto a "uno o dos muchachos que la frecuentaban, mencionándose en particular la presencia de un amoral que residía en Saladillo", un dato que sería a fin de cuentas relevante a la causa. ${ }^{33}$ Finalmente, El Plata se preguntaba: “¿realizaban sus fiestas allí?”, destacando que la construcción de la segunda casita, hacia los adentros del terreno, perseguía el objeto de lograr la discreción.

La vida equívoca que llevaba la víctima (...), lleva a la convicción de que el Señor Palma llegó a ese aislamiento, precisamente para buscar un escenario propicio y apartado de miradas indiscretas para realizar fiestas con sus amigos" ${ }^{34}$

En la definición de aquellos encuentros, los diarios hicieron hincapié en la evasión de "lo normal", reflectando con ello el modelo de domesticidad tradicional que, en efecto, Palma había abandonado luego de 33 años como esposo y padre de dos hijos.

\section{3.b. Un jubilado en boca de todos}

El matrimonio constituía un elemento relevante en la consolidación de la identidad adulta tanto de mujeres como de varones. En su estudio sobre el modelo conyugal, Cosse (2008) ha destacado que el casamiento "determinaba el carácter normal o anómalo de la trayectoria personal" (p. 74). Como sabemos, Palma se encontraba viviendo con su madre en un contexto donde el divorcio vincular no existía y no entraría en agenda al menos hasta unos años después. ${ }^{35}$ La figura que encuadraba su situación era la separación legal de cuerpos, el único recurso en vigencia que subsistía de la vieja ley de matrimonio civil de 1888 . Esta permitía la separación física de los esposos sin disolución del vínculo matrimonial, manteniendo las obligaciones contraídas. En caso de solicitar la separación, el código prescribía una audiencia en la que el juez debía oír a las partes y procurar conciliarlas, es decir que para obtener la orden efectiva, había que atravesar un recorrido que resultaría cuanto menos engorroso, estándose efectivamente comprometido a ello. ${ }^{36}$ Los familiares de Palma contaron a los diarios que la separación había sido promovida "por la naturaleza del trabajo que atendía". Este "le exigía mucha atención, lo que le provocaba un continuo estado nervioso. A causa de su irritabilidad, sostenían frecuentes reyertas con su esposa ${ }^{37} \mathrm{El}$ juez había decretado la separación favorablemente aduciendo "incompatibilidad de caracteres". Además de los causales encuadrados en la ley, la normativa plasmaba la potestad del juez para decretarlo "cuando, según su ciencia y conciencia, los motivos aducidos por las partes sean suficientemente graves. ${ }^{38}$ En este punto, y a descrédito de la irritabilidad y falta de sueño, los diarios incorporaron la hipótesis de la identidad sexual de Palma. Señalaron entonces a un joven "moreno y bien puesto (...) como el que originó, con actitudes equívocas, las divergencias de aquél con la esposa y que posteriormente motivaron la separación judicial de cuerpos". ${ }^{39}$ Sugiriendo lo mismo, El Plata indicó que "las presunciones giran ahora alrededor del drama familiar, ocurrido a raíz de la separación del Señor Palma y su vida equívoca, y entorno a sus relaciones con individuos de baja catadura moral" ${ }^{40}$

Las representaciones culturales en torno al divorcio hacían hincapié en la última opción frente a un vínculo verdaderamente irrecuperable o donde corriera riesgo la propia vida. El desprestigio asociado a ello se relacionaba con la idea de "fracaso" de la pareja y abdicación frente al modelo familiar (Cosse, 2008). No obstante, este tipo de discursos iban especialmente dirigidos a las mujeres, pues se creía que la madre debía evadir a los hijos de la exposición pública frente a los “errores" del padre. En esta clave se puede entender la repercusión de los episodios sobre el núcleo familiar de Palma, destacándose que sus hijos eran "dos excelentes y apreciados muchachos, a quienes no salpica en lo más mínimo este lamentable y oscuro hecho”. ${ }^{41}$ Los diarios salieron a resguardo de la honorabilidad del núcleo, y en todo caso explicaron el alejamiento y las conductas del padre "por esas incompatibilidades de carácter que surgen a la vejez", es decir que antes de acarrear el estigma del "invertido" era preferible representar a los lectores un personaje anciano o senil.

Por otra parte, al jubilarse, Palma despedía un empleo respetado en los círculos obreros. La historia de lucha de los ferroviarios condensaba sentidos sobre una masculinidad heroica que no obstante lograba articularse 
al ideal de domesticidad. El trabajador debía ser al mismo tiempo un militante activo y un padre presente. La familia encontraba entre los ferroviarios un ámbito de inscripción reconocido, que le permitía participar de celebraciones y encuentros sociales, así como gozar de la protección del gremio en caso de fallecimiento del afiliado (D'uva y Palermo, 2015). Esto muestra que Palma podría haber disfrutado de un retiro apacible cosechando las conquistas de una vida "exitosa", como varón proveedor con un empleo honorable durante los años que duró su matrimonio. Como se ha planteado, El Plata hizo especialmente hincapié en ello, al destacar una y otra vez el carácter del "hogar respetable al que ha enlutado este doble drama" ${ }^{42}$ Así, en la medida en que Palma encarnaba un núcleo de identificaciones que comulgaba estrechamente con los valores del peronismo, su homosexualidad resultó problemática para los cronistas, conminándoles a moderar el tono con que habitualmente comunicaban otras trayectorias "amorales" en las mismas páginas.

Por añadidura, su historia personal expresaría, en concordancia con lo expuesto por Ben (2005) aquella transición de las primeras décadas de siglo al período peronista, donde una parte de la población homosexual habría consolidado un modo de vida por fuera del "bajo fondo", resguardando su identidad en el marco de una familia "respetable".

Entendemos, así, que el sacrificio de una vida consagrada según las normas sociales hegemónicas solo podía ir detrás de la expresión de su deseo, por fin, y aunque solo fuera en sus últimos años de jubilado. A pesar del tono moralista de las crónicas, resulta coherente la lectura de su jubilación como una oportunidad para instalarse en un lugar (la casita de los fondos) que le permitiese vivir su sexualidad con mayores libertades.

Es más difícil establecer hasta qué punto aquella vivienda era el enclave de una sociabilidad homoerótica más amplia, o simplemente una isla en los suburbios. Acha y Ben (2004) han destacado que "los domicilios no constituían espacios meramente privados, sino una articulación entre lo privado y lo público que facilitaban diferentes formas de sociabilidad" (p. 18). Esto era así en la medida en que muchos se veían arrojados a vivir su sexualidad en la clandestinidad, encontrando en las casas y departamentos espacios donde protegerse de la hostilidad pública. La sugerencia de las reuniones en la casita del fondo, o cualquier otro tipo de encuentro social que habilitaran a Palma o sus visitantes la posibilidad de maquillarse y usar tacones, no resulta descartable en este marco. Otras informaciones amplían la mirada, dando cuenta de que la casa era frecuentada por distintos visitantes. Si bien Palma "se especializaba principalmente en el teñido de cabezas femeninas", como complemento a las actividades de peluquería practicaba la cartomancia y adivinación del porvenir. Según confirma El Argentino "se le encontró un grupo de naipes ingleses que usaba para ejercer la adivinación”. El testimonio del propio asesino retrata una jornada diaria del jubilado (en este caso: el día en que murió): "por la mañana, [el agresor] advirtió la entrada de una mujer morocha y gruesa que no lo vio, porque ella se introdujo en el dormitorio de Palma para que este le tirara las cartas". Además expresó “a las 14 llegó en auto una pareja, que también penetró en la habitación del morador” ${ }^{43}$ Estas referencias sugieren la existencia de un conjunto de personas que estaban permitidas como parte de aquel entorno. Volveremos sobre estas ideas en el próximo apartado, al recomponer las condiciones en que se conocieron Horacio Palma y su amante.

\section{4.}

\section{4.a. Ángel Valdez y una carta desde Saladillo.}

Clausurada la presencia de las vecinas en el escenario del crimen, la investigación tomó de lleno la dirección del "drama entre amorales". Según El Argentino, las confirmaciones del amante masculino llegaron de la mano de una carta que este le había enviado a Palma unos días antes del asesinato. La sugerencia de ir tras aquella pista vino de su hermano Normando Palma, quien recibía su correspondencia personalmente ya que le era enviada a su casa "por razones de comodidad". El hombre narró que "en una oportunidad llegó a sus manos una de 
aquellas que leyó y su contenido lo llenó de asombro e impaciencia”. ${ }^{44}$ Señaló en particular que el remitente "usaba frecuentemente la palabra querido amigo, lo que provocó la impaciencia del deponente. Eran términos -ha comentado este- más propios de una carta amorosa que de un hombre a otro" ${ }^{45}$ El Plata resultó más exhaustivo en la descripción de la misiva, señalando que "la misma está redactada en los tonos vehementes de un ser apasionado morbosamente (...) en sus términos campea la ansiedad por lograr una última cita para conservar un grato recuerdo de las relaciones que mantuvieran". A continuación se preguntaba "¿sería esa cita la que le brindó el señor Palma aquella noche en la soledad de la casita? (...) La pericia caligráfica de la carta podría dar la pista para saber quién es el amigo que quería venir de Saladillo". ${ }^{46}$

La forma en que los periodistas recuperaron el contenido de la carta repone distintas dimensiones que nos interesan destacar. En primer lugar el término amistad y amigo reflejaba un uso, por lo demás común, que evadía de nombrar el carácter de la relación por lo que era, un vínculo sexoafectivo entre dos varones. Sin embargo, inscripta en el contexto de la noticia, aquella denominación operaba de manera transparente como significante de amante. En términos lingüísticos, se producía un desplazamiento semántico de tipo metonímico, en el que un objeto era designado con el nombre de otro, evadiendo el uso de aquella palabra. A través de esta operación, la persona que enuncia logra despegarse de la carga moral del enunciado. De este modo la sociedad "de bien", encarnada en el discurso de la prensa, se construye en oposición a "los homosexuales" constituidos como una otredad radical, al punto que la homosexualidad en sí misma resulta un innombrable. Puede que esto explique la razón por la que se actualizan conceptos como amoral y anormal a pesar de que la palabra homosexual tenía vigencia en la época. ${ }^{47}$

Entre los protagonistas de los episodios, sin embargo, la historia se contaba diferente. En la declaración indagatoria el amante y asesino "narró sin ningún recato y llamando las cosas por su nombre, sus relaciones anormales con el 'viejo' Palma al que conoció hace algún tiempo, cobrándole afecto”. ${ }^{48}$ Resulta por demás sugerente que Valdez llamara a las cosas "por su nombre": el acto de nombrarse a sí mismo tenía un efecto performativo sobre la realidad pues, al hacerlo, traducía su identidad "innombrable” al plano del discurso público, afirmando su existencia (Buttler, 2002). Sin pretender una lectura de resistencia basada en microactos discursivos, interesa señalar que la vergüenza y la impaciencia eran una carga depositada en los actores externos a la historia: periodistas, funcionarios y familiares. ${ }^{49}$

Por otra parte, aunque los cronistas insistieran en reencauzar los hechos volviendo hacia las definiciones de "lo normal", transmitieron igualmente el carácter romántico en la carta de Valdez, haciendo visible el deseo. Recuperaron su voz indicando que

la distancia y el tiempo no lograron enfriar aquella amistad equívoca, y por el contario el propósito de la víctima de cortar con él motivó el envío de varias misivas, una de las cuales, de términos apasionados, fue la que sirvió para descubrirlo. ${ }^{50}$

Aún en una tercera persona distanciada del sujeto, propia del lenguaje judicial, las dimensiones emocionales y sexuales que recompone el relato resultan clarificadoras del vínculo, en un mecanismo que se acerca y toma distancia del sujeto que pretende describir a la vez.

Otro lugar ocupan las palabras de Normando, el hermano del ferroviario. A pesar de su "impaciencia" no debe exagerarse el peso de la condena inscrita en esas expresiones, a juzgar por el hecho de que recibía la correspondencia de Palma personalmente (y de hecho, la leía). La figura del "tercero" que facilita una comunicación prohibida era un tema habitual en las novelas sentimentales de la época. Si Normando no abogaba abiertamente por la relación de su hermano, al menos no representaba una amenaza a su deseo como sí lo hacía su madre, con quien compartía el terreno. Los diarios mencionaron oportunamente que los "hábitos de vida irregulares" de Horacio contrariaban a la anciana, con quien sostenía asiduas peleas.

Por añadidura, las reglas del decoro establecían usos bastante formales en los intercambios epistolares, en especial cuando se trataba de cartas amorosas. Las revistas del corazón recomendaban respetar una serie de pasos antes de utilizar términos afectuosos que tradujeran directamente las intenciones (Acha, 2008). En 
ese sentido, el uso del "querido/a" mostraba sin ambigüedades el tono afectivo de la misiva, y explicaría algo mejor las aclaraciones de Normando en relación a términos que resultaba impropios entre dos varones.

\section{4.b. La mirada del otro}

A medida que se develaba el vínculo entre Palma y Valdez, el tono de la caracterización recogía la habitual dimensión de homosexualidad como perversión. Una vez descubierta la carta, El Plata se refirió en los términos de "una relación repugnante" aunque, como ya se ha planteado, esta carga de sentido fue especialmente dirigida al homicida. Al respecto es ilustrativa la publicación de una fotografía de su rostro intervenida con flechas por los cronistas. Allí buscaron resaltar sus rasgos faciales destacando que "revelarían" una personalidad delictiva (figura 2).

FIGURA 2

Fotografía de Ángel Valdez intervenida por el Diario El Plata (8 octubre de 1948).

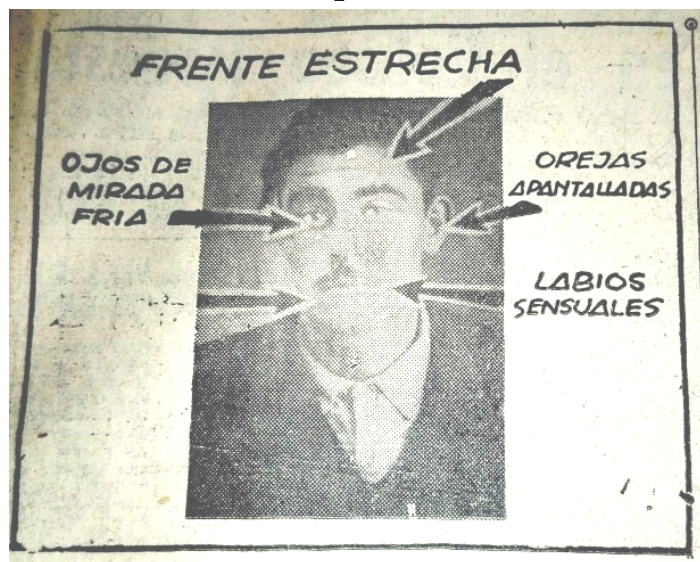

Debajo de la imagen decía:

Si es cierto que hay rostros que hablan y definen, nada más elocuente que la cara asimétrica de Ángel Valdez, para descubrir en la conformación de sus facciones los estigmas de degeneración que trasunta el crimen y sus móviles. Orejas deformadas y separadas, ojos de brillo siniestro, frente estrecha incubadora de instintos primitivos, labios sensuales e instintivos, y pómulos angulosos de perfiles mongólicos. ${ }^{51}$

Esta impactante descripción pretendía referenciarse en la antropología morfológica de fines de siglo XIX, para la cual existía una correspondencia entre los rasgos físicos y el comportamiento. La referencia a estos formaba parte de un conjunto de técnicas de disciplinamiento, cuyo fin era establecer "regímenes de verdad" que definían qué era "lo normal" y qué no lo era (Foucault, 2007). ${ }^{52}$

Las imágenes de los diarios operaron reproduciendo mensajes homofóbicos en donde la sexualidad emergía como elemento de alterización en sí mismo. La hipersexualización era asimismo común en aquellas narrativas y se conectaba con la referencia a un estado de naturaleza y animalidad. La particular mención a "los labios sensuales e instintivos" es reveladora de la capacidad productiva del discurso, siguiendo a Buttler (2002), ya que ninguna parte del cuerpo logra ser "sensual e instintiva" por fuera de la atribución de sentido que la significa. Dicho de otro modo: hay una deliberada voluntad por ligar esa boca a lo sexual como expresión de algo anterior a la cultura. Le Breton (2009) ha llamado nuestra atención hacia la jerarquía que tiene el rostro en relación a otras partes del cuerpo, en la medida en que condensa el sentimiento de identidad personal e individual. En tanto lugar que guarda "lo sagrado", es también el objeto predilecto de la profanación: la degradación del rostro es una manera "de eliminar al individuo y romper el signo de su pertenencia a la especie” (Le Breton, 2009, p. 142). Por eso mismo el rostro constituye el espacio fundamental de la expresión 
de "lo otro" que opera a través de mecanismos como "el rechazo o la animalización (...) el insulto o el racismo, o aun la desfiguración” (p. 142). Estamos así frente a un ejercicio de deshumanización de un individuo que emerge como encarnadura de "lo homosexual" o "la homosexualidad".

Una invitación a revisitar esta fotografía muestra en cambio el valioso retrato de un joven de clase trabajadora con vestimenta de los años 40: muy lejos de las tipologías de Lombroso. Fuera o no tomada en el contexto de su detención, los diarios solían destacar la actitud del detenido frente a las cámaras, fundamentalmente si miraba de frente o no. Margulies, Name y Mouján (2015) han mostrado que detrás de una mirada incómoda podía trascender el carácter de un encuentro crudamente desigual. Por su parte, Acha (2013) ha interpretado esta y otras actitudes como evidencia de cierta subjetivación entre los homosexuales del período, que avanzaría hacia la definición de una identidad grupal. En la misma clave, Gorza (2010) recupera el caso de una valiente travesti que resiste el interrogatorio de médicos y policías tras ser detenida, afirmando su identidad más allá de las atribuciones del género. En el caso de las fotografías de Valdez resulta más difícil de esclarecer, ya que esta vez sí se hace necesario incorporar su rol como asesino. El lenguaje corporal y la mirada baja, en ocasiones, traducía el sentimiento de culpa o arrepentimiento en relación al delito cometido (figura 3 ).

FIGURA 3

Ángel Valdez, “ceñudo y de mirada baja”. El Argentino (8 de oct. De 1948)

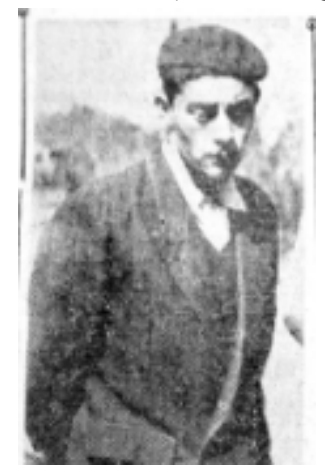

Llegados a esta punto conviene preguntarse ¿quién era Ángel Valdez y cómo había llegado a la vida de Palma?

\section{4.c. Itinerarios de un peón rural}

Valdez trabajaba en el campo. En febrero de 1948 había llegado a La Plata en busca de empleo, obteniendo uno en un vivero, a pocas cuadras de la casa del ferroviario.

Un sábado, una semana después de su llegada conoció en el almacén a Palma que se mostró quejoso de los daños que le causaban las hormigas en sus sembrados. Como el declarante le hiciera algunas indicaciones para combatir la plaga, Palma le pidió que fuera a su casa para asesorarlo, lo que así hizo, e inmediatamente le dio muestras de sus inclinaciones amorales. ${ }^{53}$

Este episodio narrado en los términos de lo fortuito, expresaba un lenguaje cultivado que permitía a dos extraños construir un escenario de intimidad. Sebreli (1997) ha explicado que esta "ceremonia de miradas, coreografías de movimientos, pequeños gestos imperceptibles al profano" (p. 340) obedecían, en parte, a la clandestinidad a la que se veían arrojados. La relación de Palma y Valdez, aunque intermitente, logró proyectarse en el tiempo y tuvo por escenario principal la casita de los fondos: "en varias entrevistas allí mismo [Valdez] estrechó su amistad con Palma".54

Las descripciones que aportaron los diarios permiten pensar a Valdez en diálogo con la figura del "chongo" que designaba a un hombre joven y viril, de clase baja, y que ocupaba el rol "activo" en la relación sexual en 
un esquema, por cierto, binario. 55 Se entendía que aquel rol ponía "a resguardo" su heterosexualidad definida por el signo positivo de una masculinidad dominante o penetradora. Por añadidura, el carácter popular del estereotipo dialogaba con algunas referencias que indicaban su interés en la seducción de hombres mayores y mejor ubicados a cambio de favores económicos o simplemente un lugar donde pasar la noche. ${ }^{56}$

La precaria situación económica de Valdez alimentó un circuito de movilidad que reproducía pautas comunes a toda la población joven en busca de trabajo o esparcimiento. Este revelaba dos movilidades superpuestas: una que iba del interior a la capital provincial y otra que iba del barrio al centro.

Las trayectorias de homosexuales provincianos que buscaban en las ciudades ámbitos algo más amables para vivir, son habituales en las novelas urbanas que retratan los años 50. Peralta (2013) ha trabajado esta figura identificándola en las novelas de Renato Pellegrini, Mujica Laínez, Manuel Puig y Carlos Correas, entre otros. Estos escritos recrean la experiencia subjetiva de la migración aportando interesantes matices (en Pellegrini, por ejemplo, los provincianos no son el estereotipo del "cabecita" sino hombres blancos), a la vez que recogen las trayectorias personales de los propios autores como migrantes homosexuales. Estos recorridos y el del propio Valdez permiten pensar las movilidades de manera más amplia, asociadas tanto al ciclo económico y el empleo, como al deseo y la identidad sexual. ${ }^{57}$

La sociabilidad homoerótica de los años 50 en la Capital Federal fue reflejada en los términos de una "subcultura", a tono con la imagen de una "ciudad dentro de la ciudad", con un circuito específico y lugares donde se mantenían los encuentros a resguardo de miradas ajenas (Simonetto, 2017). Un registro similar puede encontrarse en los casos analizados aquí como cuadratura de las noticias policiales: la calle, la estación de trenes, el cine emergen como escenarios de encuentro, configurando este un fenómeno de las grandes ciudades. Este planteo forma parte de aquella tensión inscrita en la mirada de los otros al respecto de algo que "ocurre a la vista de todos", pero que al tiempo se dice desconocer y se excluye de manera radical en el discurso.

El caso de "las casitas gemelas" incorpora el barrio al circuito urbano, revelando la existencia de una sociabilidad cruzada, muy ilustrativa de la dinámica social del primer peronismo, en donde hay lugar para figuras como la Criolla o el propio Valdez como migrante y peón rural.

Para finalizar deseamos señalar, una vez más, que Valdez sí reflejaba un universo popular ligado al mundo del delito que, como se ha destacado, acompasaba trayectorias obreras sin representar, necesariamente, términos morales antagónicos (Acha, 2013) ${ }^{58}$ Este perfil dialoga con el tono general de las noticias trabajadas en el segundo apartado. En cambio, Palma representaba un entorno de clase trabajadora respetable que generaba contradicciones en los cronistas, y que su vez le permitió contar con mayores elementos que pusieran "a resguardo" su sexualidad. i Al ser detenido se evidenció que Valdez tenía antecedentes penales por hurtos y robos.

\section{Conclusiones}

En este trabajo hemos profundizado sobre un caso que permite adentrarse en las relaciones homosexuales en su inscripción barrial, en las afueras de la ciudad de La Plata, durante el primer peronismo. Buscamos esclarecer con ello la experiencia de homoerotismo en un contexto no tan transitado por la historiografía, a pesar de que sus protagonistas dialogan con figuras muy presentes en la literatura que recoge la sociabilidad de los años 40 y 50.

Una mirada amplia a un conjunto de casos permitió ver la matriz de "heterosexualidad obligatoria", que incurrió en la alterización de las identidades sexuales no convencionales, reforzando su carácter foráneo y su vinculación con la estafa, el abuso y la corrupción de menores. Por lo mismo, los casos de homicidio tienden a mostrar que los términos opuestos de la variable "víctima y victimario" se igualaban en la inscripción general del "bajo fondo". 
Sin embargo, el caso de "las casitas" reveló un tratamiento particular, atendiendo al núcleo de identificaciones que la figura de Palma condensaba en relación al peronismo. Como obrero ferroviario y padre de una familia respetable, su identidad no pudo ser abordada livianamente en los términos de la "perversión", razón por la cual los cronistas desarrollaron un tratamiento ambivalente de su figura. Forzaron la participación de mujeres en los episodios, y hasta tipificaron la imagen de un jubilado nervioso y senil, cuyas derivas identitarias estarían ligadas a una crisis del vínculo conyugal y la tercera edad. Una vez confirmada la participación de Valdez, la noticia se reinscribió en el marco de un discurso normalizador que vinculó, especialmente a este último, al mandato inmodificable de la naturaleza.

A pesar de su impronta policial, la historia logra revelar que aquella peluquería de barrio configuró un espacio habitable para un conjunto de personas cuyas identidades se expresaban por fuera de la norma heterosexual, dejando al descubierto la existencia de resquicios en el orden de género.

\section{REFERENCIAS}

Acha O. (2013). Ambivalencias del deseo, homosexuales y retórica política. En Cronica sentimental de la argentina peronista. Sexo, inconsciente e ideología 1945-1955. Buenos Aires: Prometeo.

Acha, O. y Ben, P. (2004-5). Amorales, patoteros, chongos y pitucos. La Homosexualidad masculina durante el primer Peronismo (Buenos Aires, 1943-1955). Trabajos y Comunicaciones, 30-31, 217-261.

Acha, O. (2008). Cartas de amor en la Argentina peronista: construcciones epistolares del sí mismo, del sentimiento y del lazo político populista. Nuevo Mundo Mundos Nuevos, 8.Disponible en: http://nuevomundo.revues.org/ document 12272.html [Consultado: 15/10/20].

Bazán, O. (2010). Historia de la homosexualidad en la Argentina. Argentina: marea.

Belucci, M. (2010) Orgullo. Carlos Jáuregui, una biografía política. Buenos Aires: Emecé.

Ben, P. (2000). Muéstrame tus Genitales y te diré quién eres. El 'hermafroditismo' en la Argentina Finisecular y de Principios del Siglo XX. En O. Acha y P. Halperin (eds.), Cuerpos, géneros e identidades: Estudios de Historia de Género en Argentina. Buenos Aires: Ediciones del Signo.

Ben, P. (2014). La ciudad del pecado: moral sexual de las clases populares en la Buenos Aires del 900. En Moralidades y comportamientos sexuales. Argentina 1880-2011. Buenos Aires: Editorial Biblos.

Buttler, J. (2002). Cuerpos que importan. Sobre los limites materiales y discursivos del sexo. Buenos Aires: Paidós.

Connel, R. (1997). La organización social de la masculinidad. En Valdés y Olavarría, Masculinidad/es. Poder y crisis. Santiago: ISIS-FLACSO: Ediciones de las Mujeres n 24.

Cosse, I. (2008). El modelo conyugal en la ciudad de Buenos Aires de la segunda posguerra: el compañerismo de complementariedad y el impulso familiarista. Trabajos y Comunicaciones, 34, 63-94.

D'uva, F. y Palermo, S. (2015). Vida sindical y sociabilidades masculinas: los trabajadores ferroviarios en la Argentina de principios del siglo XX. Archivos, 4(7), 37-58

Di Salvo, L. (2020). Desfondar el "caso". Transiciones masculinas en el ojo de la prensa sensacionalista argentina. Moléculas Malucashttps://www.moleculasmalucas.com/post/desfondar-el-caso [consultado: 02/04/2021].

Foucault, M. (2007). Historia de la sexualidad. La voluntad del saber. México: Siglo XXI Editores.

Ginzburg, C. (2016). El queso y los gusanos. El cosmos según un molinero del siglo XVI. Barcelona: Ediciones Península.

Giordano, V. y Valobra A. (2014). El divorcio vincular a través de los fallos judiciales: 1955-1956. Derecho y ciencias sociales 10, 2-23. Disponible en http://www.memoria.fahce.unlp.edu.ar/art_revistas/pr.8940/pr.8940.pdf

Gorza, A. (2010). Médicos civilizados, sexualidades perversas: Una mirada médica de las identidades de género no convencionales durante el primer peronismo (1946-1955). Trabajos y Comunicaciones, 36, 187-202.

Guy, D. (1991). Prostitutas patriotas y hombres peligrosos. En D. Guy, El sexo peligroso. La prostitución legalen Buenos Aires, 1875-1955. Buenos Aires: Sudamericana. 
Insausti, S. (2015). Los cuatrocientos homosexuales desaparecidos: memorias de la represión estatal a las sexualidades disidentes en Argentina. En D. D’Antonio (comp.), Deseo y represión. Sexualidad, género y Estado en la historia argentina reciente. Buenos Aires: Ediciones Imago Mundi.

Insausti, S. y Peralta, J.L. (2018) "Cuaderno bibliográfico: estudios sobre masculinidades y diversidad sexual en Argentina”. Anclajes, vol XXII, n 3, setiembre-diciembre 2018, pp. 91-117.

Kimmel, M. (1997). Homofobia, temor, vergüenza y silencio en la identidad masculina. En Valdés y Olavarría, Masculinidad/es. Poder y Crisis. Santiago: ISIS-FLACSO: Ediciones de las Mujeres n 24.

Le Breton, D. (2009). El rostro y lo sagrado: algunos puntos de análisis. Universitas humanistica, 68.

Maffia, D. (2003). Los sexos, ¿son o se hacen? En Sexualidades Migrantes, Género y Transgénero. Buenos Aires: Feminaria.

Margulies, S. Name, M.J. y Mouján, A. (2015). Damiana exige un nombre: Kryygi. La realización de un film entre docencia, investigación antropológica y cine documental. Ponencia presentada en el IV Congreso Latinoamericano de Antropología, México DF, 7 al 10 de octubre.

Milanesio, N. (2005). Redefining Men's Sexuality, Resignifying Male Bodies: The Argentine Law of Anti-Venereal Prophylaxis, 1936. Gender \& History, 17(2), 463-491.

Miranda, M. (2015). En torno a una historia de la sexualidad desde el biopoder (Argentina, siglo XX). Biblioteca del Congreso de la Nación; Boletín de la Biblioteca del Congreso de la Nación; 129.

Miranda, M. y Vallejo, G. (2004) “Los saberes del poder: eugenesia y biotipología en la Argentina del siglo XX”, Revista de Indias, vol. LXIV, núm. 231, pp. 425-444

Peralta, J. L. (2013). Espacios homoeróticos en la literatura argentina (1914-1964) (Tesis Doctoral). Universitat Autonoma de Barcelona. Departamento de filología española. Recuperada de https://www.tdx.cat/handle/10 $803 / 117190$

Ramacciotti, K. y Valobra, A. (2006). ¡Peor que putas! Tríbadas, safistas y homosexuales en el discurso moral hegemónico del campo médico, 1936-1954. En Seminário Internacional Fazendo Gênero 7 [CD ROOM]. Brasil: Editorial Mulheres.

Rich, A. (1986). Heterosexualidad obligatoria y existencia lesbiana. En Sangre, pan y poesía. Prosa escogida: 1979-1985. Barcelona: Icaria Antrazyt.

Salessi, J. (1995). Médicos maleantes y maricas. Higiene, criminología y homosexualidad en la construcción de la nación Argentina. (Buenos Aires: 1871-1914). Rosario: Beatriz Viterbo Editora.

Sebreli, J.J. (1997). Historia secreta de los homosexuales en Buenos Aires. En Escritos sobre escritos, ciudades bajo ciudades, 1950-1997. Buenos Aires: Sudamericana.

Simonetto, P. (2017). Fronteras del deseo. Homosexualidad, sociabilidad y afecto en la ciudad de Buenos Aires (1950-1983). cadernos pagu, 49. Recuperado de https://doi.org/10.1590/18094449201700470014

Simonetto, P. (2019). Perón y las visitadoras: masculinidad, consumo sexual y resistencias militares a la abolición de la prostitución reglamentada, Argentina, 1936-1955. História, Ciências, Saúde - Manguinhos, 26(2), 427-443.

Van Dijk, T. (1990) La noticia como discurso. Comprensión, estructura y producción de la información. Buenos Aires: Editorial Paidós.

\section{Notas}

1 Se utilizan nombres ficticios para preservar la identidad de las personas involucradas.

2 En la práctica, los edictos otorgaban independencia a la policía para actuar más allá del Poder Judicial, resultando en constantes detenciones arbitrarias (ver Decreto 10868/46). Estas pueden vislumbrarse en la larga duración, si se considera la proyección temporal que tuvieron (tanto en dictadura como más allá de la apertura democrática) según lo muestra la lucha de organizaciones como el FLH en los 70 y la CHA y Gays DC por la derogación de los edictos en los 80 y 90 (Belucci, 2010; Insausti, 2015 y Simonetto, 2017). Aún con matices, la bibliografía que se ocupa del primer peronismo coincide en señalar al año 1954 como un momento clave en la escalada represiva hacia las identidades no hegemónicas. Estos se amparan en un conjunto de testimonios y memorias en ese sentido. Sin embargo aún se discute el 
papel de la Iglesia y los propósitos del Estado, que contemplan sus políticas sanitarias y familiaristas, e/o. Esta discusión excede a nuestro trabajo, sin embargo, sugerimos consultar Acha (2013), Cosse (2008), Guy (1991), Insasuti (2015), Ramacciotti y Valobra (2006) y Miranda, (2015), además de las autoras y autores mencionados a lo largo del trabajo, en especial, a propósito de la Ley de Profilaxis Social de las enfermedades Venéreas (1936).

3 Acha y Ben (2004-05) plantean asimismo que en este período emerge la imagen de conjunto de varones que ya no pertenecen al ámbito de "la mala vida", teniendo la posibilidad de ocultar sus relaciones con otros para representarse como señores respetables de familia. Este sería sin dudas el caso del "Señor Palma".

4 Cabe aclarar que el trabajo también incorpora referencias al diario El Argentino. Sin embargo, estas tienen como fin ofrecer un contrapunto al abordaje de El Plata, sobre el cual se apoya la hipótesis.

5 Esta impresión se recoge a nivel global, si tomamos por caso el Informe Kensey (1948 y 1953) que puso en cuestión la heterosexualidad como norma en las sociedades modernas.

6 La demanda se había instalado como consecuencia de la Ley de profilaxis social de 1936. Con la llegada de Farrell al poder se permitieron los prostíbulos aledaños a cuarteles (1944), convirtiéndose en ley en 1947. Finalmente, en medio del conflicto con la Iglesia, Perón abolió por decreto la Ley de Profilaxis (1954). Además de los/las autores mencionados, Milanesio (2005) representa junto con Simonetto (2019) un análisis que desplaza el eje de la prostitución a las masculinidades.

7 Otro episodio público fue la expulsión de la compañía actoral de Miguel de Molina (1944), quien sería nuevamente invitado al país y recibido por Evita. Sobre este tema se sugiere ver Bazán (2010).

8 Esta expresión fue acuñada por el diputado nacional Horacio Haramboure, en 1948, a propósito de la inauguración de una sede de El Plata en Ensenada. A la inauguración asistieron distintos referentes del peronismo histórico del 45, que lo serían también de la resistencia peronista, como Juan Collazo y Manuel Bianchi.

9 Algunos casos de 1947 fueron incorporados como antecedentes valiosos. En relación a Chasal, por ejemplo, los cronistas de años posteriores lo mencionan una y otra vez al inicio de sus notas indicando: "este episodio reviste características similares al del belga B.C.".

10 "La policía ha identificado ya al dueño del cuchillo con el que fue degollado el mucamo F.C." (23 de junio 1947), El Plata, p. 4.

11 "La policía ha identificado ya al dueño del cuchillo con el que fue degollado el mucamo F.C." (23 de junio 1947), El Plata, p. 4.

12 "La policía ha identificado ya al dueño del cuchillo con el que fue degollado el mucamo F.C." (23 de junio 1947), El Plata, p. 4.

13 "Perpetraban robos dos amorales tocados con prendas femeninas" (16 de julio 1948). El Plata, p. 6.

14 "El asesino de W. Gauna huyó vestido de mujer" (20 de julio 1948). El Plata, p. 6.

15 "Perpetraban robos dos amorales tocados con prendas femeninas" (16 de julio 1948). El Plata, p. 6.

16 "Detuvieron a asaltantes de amorales" (Noviembre de 1948). El Plata.

17 "Otro suicidio: eslabona a la muerte de L. A., el estrangulado del arroyo del medio" (14 de diciembre de 1948). El Plata, p. 7.

18 “Alarma en Sidney el homosexualismo" (14 de diciembre de 1948). El Plata, p. 7.

19 Un conjunto de casos que quedaron por fuera remiten a: la detención de un "amoral" boliviano en Tigre (junio, 1948); el asesinato de un policía "provincianito” que mantenía relaciones con varias mujeres y varones (noviembre, 1948); el suicidio de un brasileño (diciembre, 1948); el asesinato de un menor y el posterior suicidio de su "amante" (septiembre,, 1948) y un "amoral" que robaba junto a una sirvienta (junio, 1948) y un curandero y amoral (octubre, 1948).

20 Usamos "homosexualidad femenina" porque la acepción "lesbiana” tenía poca representación en la época. El campo médico utilizó "tríbadas y safistas" (Ramacciotti y Valobra, 2006) mientras que en el uso popular existieron distintos nombres e identificaciones (Figari y Gemetro, 2014; Fiorucci, 2012). Por último, ese uso sin dudas no tenía la impronta política de afirmación identitaria que hoy representa.

21 Los estudios sobre homosexualidad femenina durante el primer peronismo han ratificado la invisibilización que operó en la prensa (Ramacciotti y Valobra, 2014), mientras que los estudios sobre homosexualidad masculina dialogan ofreciendo una explicación para mostrar la particular visibilidad que adquieren las masculinidades homosexuales en el período (Acha y Ben, 2004-05). No obstante, es posible rastrear otro conjunto de noticias relativas a masculinidades trans, configuradas por el discurso periodístico en la clave de trasgresiones la feminidad heterosexual. Para ver su tratamiento como "noticia espectacular" ver Di Salvo (2020), especialmente para los años 60 y 70 en Argentina.

22 "De un momento a otro ha de quedar develado el misterioso crimen de las casitas gemelas" (6 de octubre). El Plata, p. 5.

23 "Una octagenaria y su hijo fueron misteriosamente ultimados mientras reposaban en su dormitorio" (6 de octubre de 1948). El Argentino, p. 10.

24 "Una octagenaria y su hijo fueron misteriosamente ultimados mientras reposaban en su dormitorio" (6 de octubre de 1948). El Argentino, p. 10. 
25 "Una octagenaria y su hijo fueron misteriosamente ultimados mientras reposaban en su dormitorio" (6 de octubre de 1948). El Argentino, p. 10.

26 "Una octagenaria y su hijo fueron misteriosamente ultimados mientras reposaban en su dormitorio" (6 de octubre de 1948). El Argentino, p. 10.

27 "De un momento a otro ha de quedar develado el misterioso crimen de las casitas gemelas" (6 de octubre). El Plata, p. 5.

28 "La investigación del doble asesinato gira en torno a un sospechado y un papel con manchas de rouge" (7 de octubre de 1948). El Argentino, p. 7.

29 "La investigación del doble asesinato gira en torno a un sospechado y un papel con manchas de rouge" (7 de octubre de 1948). El Argentino, p. 7.

30 "Se volvió a trabajar en torno a una venganza familiar sin descartar un drama entre amorales" (7 de octubre). El Plata, p. 6.

31 "Se volvió a trabajar en torno a una venganza familiar sin descartar un drama entre amorales" (7 de octubre).El Plata, p. 6.

32 "De un momento a otro ha de quedar develado el misterioso crimen de las casitas gemelas" ( 6 de octubre). El Plata, p. 5.

33 "De un momento a otro ha de quedar develado el misterioso crimen de las casitas gemelas" ( 6 de octubre). El Plata, p. 5.

34 "Se volvió a trabajar en torno a una venganza familiar sin descartar un drama entre amorales" (7 de octubre). El Plata, p. 6.

35 La ley 14.394 de divorcio vincular se sancionó en 1954 y estuvo en vigencia brevemente tras ser derogada, en una escalada conservadora, por el gobierno de facto inaugurado en 1955.

36 Para ver los causales de divorcio contemplados en la ley, consultar arts. 67 y 67 bis.

37 "Una octagenaria y su hijo fueron misteriosamente ultimados mientras reposaban en su dormitorio" (6 de octubre de 1948). El Argentino, p. 10.

38 La ley de 1954 no eliminó aquellas causales del viejo código. Al estudiar los fallos, Giordano y Valobra (2014) han destacado que, contrario a lo que normalmente se creyó, estos no representaron una tendencia a vindicar especialmente las posiciones femeninas, resultando una herramienta también en manos de los esposos. Se advierten así las distancias entre la norma y la práctica de su aplicación, plagada de preconceptos sobre los géneros.

39 "Una octagenaria y su hijo fueron misteriosamente ultimados mientras reposaban en su dormitorio" (6 de octubre de 1948). El Argentino, p. 10.

40 "Se volvió a trabajar en torno a una venganza familiar sin descartar un drama entre amorales" (7 de octubre). El Plata, p. 6.

41 "Se volvió a trabajar en torno a una venganza familiar sin descartar un drama entre amorales" (7 de octubre). El Plata, p. 6.

42 "De un momento a otro ha de quedar develado el misterioso crimen de las casitas gemelas" ( 6 de octubre). El Plata, p. 5.

43 "Fue detenido en Saladillo y traído a esta ciudad el autor del alevoso crimen de la octogenaria y su hijo" (8 de octubre de 1948). El Argentino, p. 7.

44 "Fue detenido en Saladillo y traído a esta ciudad el autor del alevoso crimen de la octogenaria y su hijo" (8 de octubre de 1948). El Argentino, p. 7.

45 "Fue detenido en Saladillo y traído a esta ciudad el autor del alevoso crimen de la octogenaria y su hijo" (8 de octubre de 1948). El Argentino, p. 7.

46 "Se volvió a trabajar en torno a una venganza familiar sin descartar un drama entre amorales" (7 de octubre). El Plata, p. 6.

47 Los periodistas no desconocían el término. Antes bien, parece coherente la idea de que cuando la carga moral era insoportable, no se atrevían a usarlo. Peralta (2013) ha sugerido que existía algo parecido con el término tenebrosos, utilizado para designar a cafiolos y prostituyentes.

48 “Miente deliberadamente el asesino de P. y la Octagenaria: ¡lo mató mientras dormía!" (8 de octubre). El Plata. p. 7.

49 Estas expresiones dialogan con la tesis de Acha en relación a pensar el surgimiento de una suerte de conciencia e identidad homosexual para el período, idea que retomaremos en el próximo apartado.

50 “Miente deliberadamente el asesino de P. y la Octagenaria: ¡lo mató mientras dormía!” (8 de octubre). El Plata. p. 7.

51 “Miente deliberadamente el asesino de P. y la Octagenaria: ¡lo mató mientras dormía!” (8 de octubre). El Plata. p. 7.

52 En la misma clave, las investigaciones de Miranda y Vallejo (2004) permiten pensar estos discursos en el marco de un diseño biopolítico más amplio. Les autores han señalado la influencia de las perspectivas biotipológicas en áreas relevantes del Estado como las de salud, educación e inmigración en este período.

53 "Fue detenido en Saladillo y traído a esta ciudad el autor del alevoso crimen de la octogenaria y su hijo" (8 de octubre de 1948). El Argentino, p. 7.

54 "Fue detenido en Saladillo y traído a esta ciudad el autor del alevoso crimen de la octogenaria y su hijo" (8 de octubre de 1948). El Argentino, p. 7.

55 El "esquema mediterráneo de la sexualidad" es arduamente discutido ya que resulta esencialista, asumiendo roles fijos que hacen poca justicia al carácter fluido de las identidades. Ver Insausti y Peralta, (2018).

56 Véase, por ejemplo, "La narración de la Historia" de Carlos Correas.

57 Lo mismo opera para provincianas jóvenes que vieron en la migración una oportunidad para desprenderse del yugo familiar en los lugares de origen, obteniendo la oportunidad de "relajar" los mandatos morales en el marco de la ciudad.

$58 \mathrm{Al}$ ser detenido se evidenció que Valdez tenía antecedentes penales por hurtos y robos. 